Aletria, Belo Horizonte, v. 28, n. 2, p. 85-100, 2018

\title{
La errancia interior en Todo aquí es polvo de Esther Seligson
}

\section{The inner wandering in Everything Here is Dust by Esther Seligson}

\author{
María Esther Castillo García \\ Universidad Autónoma de Querétaro, Santiago de Querétaro, Querétaro / México \\ marescas2014@gmail.com
}

Resumen: Este artículo analiza la poética de una travesía interior expresada por Esther Seligson en su libro Todo aquí es polvo. Nos interesa destacar que la carga cultural de sus antepasados provocó grietas y pesares hereditarios como una segunda capa identitaria, tal estado de existencia se articula a través de la palabra propia y de aquellas ideas provenientes de filósofos en exilio, de escritoras de ascendencia judía como ella y de otras referencias entre las que destaca el pensamiento de Gaston Bachelard.

Palabras clave: Esther Seligson; emigración; judeidad; poética.

Abstract: This article analyzes the poetics of an interior journey expressed by Esther Seligson in her book Everything Here is Dust. We're interested in pointing out that the cultural load of her ancestors caused cracks and hereditary regrets, as a secondary identity layer, such existential state is articulated through the word of her own, and through the ideas of philosophers in exile, through Jewish women writers such as herself, and through other references that highlight Gaston Bachelard's thinking.

Keywords: Esther Seligson; emigration; Jewishness; poetics. 
“Hay algo que llamo 'síndrome seligson' que no es similar al destino de los Átridas, pero lleva en nuestra sangre una especial sensibilidad para la autodestrucción, que tampoco se trata de un privilegio o Gracia, pues cada familia carga por ahí una 'semilla maldita', de otra manera no habría Literatura".

Esther Seligson

Esther Seligson (1941-2010) fue una escritora que abarcó por igual todos los géneros. La escritura de poesía, prosa y drama armonizaba con sus trabajos de traductora además de investigación y administración. Como traductora, los textos de Emmanuel Lévinas, Michel Cioran y Edmond Jabès son imprescindibles en su repertorio de ideas y propuestas literarias. Seligson fue becaria del Centro Mexicano de Escritores y ganadora del Premio Xavier Villaurrutia en 1973 por su novela, Otros son los sueños, así como del premio Magda Donato en 1989. Sus primeros escritos fueron difundidos a través de la prensa, revistas nacionales y editoriales como Artifice y Ediciones sin nombre; en la actualidad gran parte de su obra se reúne en antologías: A campo traviesa (2005), Toda la luz (2006), Negro es su rostro - Simiente (2010). ${ }^{1}$ El período literario de su producción tiene correspondencias con escritoras de la generación de "Medio Siglo": Enriqueta Ochoa, Julieta Campos o Muñíz-Huberman, entre otras, fueron ávidas espectadoras de la modernidad artística europea. En la obra de Seligson se destaca sobre todo las influencias de Virginia Woolf, Marcel Proust y Marguerite Duras; en el mismo tenor debemos enfatizar la esencia mística de sus reflexiones y anticipar el encuentro espiritual con Las Moradas de Teresa de Ávila (1580), que mucho esclarece su propia novela, La morada del tiempo (1981), y que casualmente armoniza con el libro, Morada interior (1972), escrita por Angelina Muñiz-Huberman, otra contemporánea en época, ideas y procedencia judía. Muñiz-Huberman es una escritora que, en en el libro citado, crea -o recrea- un personaje cuya única posibilidad de

${ }^{1}$ Ediciones anteriores: Tras la ventana un árbol (1969), Otros son los sueños (1973), Vigilia del cuerpo (1977), De sueños, presagios y otras voces (1978), Luz de dos (1978), Diálogos con el cuerpo (1981), La morada en el tiempo (1981), Sed de mar (1987), Indicios y quimeras (1988), Isomorfismos (1991), además de tomos de recopilación de ensayo literario o reflexión sobre el teatro. En Tríptico (1993) se reunieron: Otros son los sueños, Diálogos con el cuerpo y Sed de mar. 
existencia real es hacia adentro, ahí leemos la lucha erótico-divina de la narradora y la conciencia de un pasado judío en su transición hacia el cristianismo. En las dos escritoras se aprecia una constante entre la mística del siglo XVI y la tendencia cultural del cosmopolitismo europeo del $\mathrm{XX}$, en ambas fluye una temática centrada en la soledad, la aflicción, la extrañeza, la frustración del amor, la inquisición de la memoria, el sino del exilio y la muerte, cada premisa conmueve y motiva su poética. Muy cercanas también a las ideas de la filósofa española María Zambrano, ${ }^{2}$ Seligson y Muñíz-Huberman, asumen que la historia de Occidente ha sido un relato de historia sacrificial, en donde lo que más resalta es el sentimiento de orfandad. Esta sensibilidad se trasluce también en la obra de E. Jabès, fuente inagotable en la conciencia espiritual de Seligson. Muñíz-Huberman, precisamente, sugiere ${ }^{3}$ que el exilio es el factor que más ha conmovido a la desesperanza al quebrantar el interior de quien lo padece o hereda:

Un exilio que todos llevamos dentro. La conciencia de que el exilio es una parte necesaria de la vida como lo es del texto bíblico, un largo paso entre el proceso de madurez y comprensión. Una vuelta de tuerca para la construcción del edificio de la memoria. Para que la historia prevalezca. ${ }^{4}$

Tal interpretación de exilio interior, marcha por igual al compás de una memoria que se teje entre dos fuerzas rectoras, el movimiento y la ruptura. Un sino de errancia signa los antecedentes familiares que la escritora articula a través de la palabra. La memoria en la palabra es la secuela de una vida figurada por alguien como ella, que, como muchos y muchas compatriotas, la incluye en esa segunda generación de inmigrantes; los padres judíos, al emigrar a México, conservaron el cariz de una expedición dolorosa que trazaría el ambiente en el que crecieron Esther y su hermana.

Todo aquí es polvo originalmente iba a ser una novela, pero viró a escritura autobiográfica al convocar las referencias de herencia judía; los antecedentes peregrinos de sus padres signaron de manera distinta tanto los tiempos de infancia en México, como el constante errar entre

\footnotetext{
${ }^{2}$ ZAMBRANO. Persona y democracia.

${ }^{3}$ MUÑIZ-HUBERMAN. El libro del desencanto, [s.p.].

${ }^{4}$ MUÑIZ-HUBERMAN. El libro del desencanto, [s.p.].
} 
París, Madrid, la India, Lisboa; pero es el viaje hacia Jerusalem y de vuelta a México, el que impulsa las imágenes de errancia aún más que el de los padres cuando cruzaron el océano después de forzosos recorridos anteriores. Esta situación del acontecer errante se complementa con una galería de lecturas filosóficas y literarias, todas ellas le "desnudan el alma".

La situación de errancia se refracta en la escritura, el texto semeja un "lugar de paso" (o rito de pasagge), ${ }^{5}$ el que deja correr la conciencia de su ser como el compendio de reflexiones intimistas y filosóficas. El libro se convierte en el espacio en donde la autora desentraña un yo vinculado al pasado y un yo emancipado y consciente, cuando puede desbrozar las situaciones vividas para poder expresarlas mediante la escritura poética. El sentimiento ensimismado de la infancia, juventud y madurez conjuga la comprensión y la rebeldía ante el desmoronamiento familiar y las implicaciones culturales que afectaron su descendencia. Para comprender el contenido que primero se quería ficción y después se convierte en autobiografía, habría de aceptarse la contradicción de que aceptar la vida es proponer una explicación de la existencia y ésta necesariamente es un relato "que nos contamos a nosotros mismos, como sujetos, a través de la rememoración". ${ }^{6}$ Esta condición, de por sí compleja, demanda que la imaginación se debata entre el poder inquisitivo de la razón y los dilemas de la pasión, el discurso revela una presión interpretativa a partir de una secuencia de interpelaciones: "¿Puede uno dejar de tener un punto de vista parcial y subjetivo? ¿Acaso nuestros afectos son sólo proyección de carencias infantiles? ¿Me puse siempre a merced del objeto amado fuera o no correspondida?". ${ }^{7}$ Entre una serie de nombres de pensadores como Lévinas y Ciroran, arbitran los preceptos de Gaston Bachelard, sobre todo para conjugarlos con las formas líricas y ensayísticas de Edmond Jabès. ${ }^{8}$ Los intereses metafísicos del primero y la forma "exegética" del

\footnotetext{
${ }^{5}$ GENNEP. Los ritos de paso. Un rito de paso (pasagge) es el que marca el movimiento o cambio de un estado a otro (condición/ existencia) de cada persona. Se considera un fenómeno cultural universal que puede mostrar jerarquías sociales, valores y creencias. Tales estados/rituales se han estudiado, sobre todo, desde el punto de vista etnológico. ${ }^{6}$ MOLLOY. Acto de presencia, p. 16.

${ }^{7}$ SELIGSON. Todo aqui es polvo, p.108-109.

${ }^{8} \mathrm{JABÈS}$. El libro de las preguntas. Una aparente confusión de géneros confecciona la estructura del libro, el autor sigue las pautas de la melitzá, un tipo añejo de escritura hebraica donde se mezcla la prosa libre con la cadenciosa, las fórmulas cortas con las
} 
segundo, convergen en la propuesta narrativa del texto. La secuencia de imágenes del recuerdo y del presente se alterna en la estructura capitular a través de un discurso pleno de paradojas y aforismos, de digresiones y enunciados descriptivos que expresan la tensión cognitiva y pasional con la que este libro está escrito.

Todo aquí es polvo, en consecuencia, como bien advierte el comentario en la contraportada del libro, se resiste a la nominación de un género definido como puede ser la autobiografía. En el trayecto encontramos la crítica literaria, los referentes autobiográficos, las anécdotas y el ensayo filosófico, en superposición de pasajes ficcionales y poéticos. El cúmulo de experiencias, percepciones e incertidumbres, postergan el mundo inaugural que se propaga y toma forma en las evocaciones e invocaciones ${ }^{9}$ realizadas por un sujeto adulto, cuando requiere hablar de la infancia como el origen de los estragos familiares. Subsiste un "sentimiento de infancia" en la lógica de un pensar e reinventar tiempos y espacios; un desborde de la conciencia se adecua en la elección de los subtítulos y epígrafes de cada sección en donde la historia infantil interviene en la vida adolescente y madura, anudando los retazos de una vida que cunde discursivamente en una voz que nunca se aleja de la primera persona. El libro se divide en cuatro capítulos: el primero reúne tres apartados: "Ella, mi madre", "Ella mi hermana", "Él mi padre"; el segundo: "Mi infancia tiene olor a nata fresca"; el tercero: "Sacerdotes sin reino y sin corona" y el cuarto: "Una ventana con cortinas al aire".

disquisiciones profundas y los versos entrelazados con otros versos sueltos a modo de adagios. Asimismo, la forma de enunciar las sentencias de los "falsos rabinos" (de los que se vale Jabès para emitir sus propios pronunciamientos) recuerda a la tradición hasídica. Las numerosas menciones al valor simbólico de las letras provienen asimismo de la Cábala. Jabès es un parangón importante cuando se estudia la obra de Seligson, incluso en relación con ese estilo antiguo de escritura hebraica.

${ }^{9}$ Aquí el autor refiere la imagen de infancia a partir de dos hitos, evocación e invocación, es decir: Proust vs. Joyce, ambos presentan, según el autor, "dos modos arquetípicos mediante los cuales a los adultos les es permitido volver a la infancia [...]. La evocación se atiene a los datos perceptivos, pero se expresa en términos lógicos [...] La invocación de la infancia en Joyce es, en cierto modo, la concreción de una fórmula mágica que permite remontar el río de los años para llegar hasta los orígenes" (ELIZONDO. Cuaderno de escritura, p. 18 y 26). 
En la profusión de intereses culturales, ${ }^{10}$ se destaca el leitmotiv que poéticamente cohesiona el texto. Éste se conjuga en una frase los atesorados instants of being, ${ }^{11}$ que podemos traducir en epifanía o en goce, motivo que establece un claro contraste entre el padecer de la narradora en tanto sujeto de su escrito: lo penoso, la fuerza silenciosa de lo oculto, las sombras de un irresuelto pretérito y los instantes de plenitud. Tales instantes se pronuncian como formas de "habitar el gerundio del ser", de un estar/ser/siendo, ${ }^{12}$ que destaca el pensamiento filosófico de Bachelard. Esa disposición del ser/estar que habitamos, aprehensible en la memoria, él la refiere encapsulada para convertirse en otra cosa, en este caso en cualidad poética de lo lírico, se identifica en el "como si" de una "metafísica instantánea", un entrecruce de filosofía y poesía en donde concurre la visión del universo y el secreto del alma en un solo instante pleno de ambivalencias en donde "mediante un singular encuentro virtual la naturaleza del acto es ser actual"; ${ }^{13}$ con este matiz temporal (cercano a Bergson) de una versión poética de la vida, la narración de Seligson se experimenta como una exégesis entre dos sentimientos ambivalentes: éxtasis y temor, siempre en colisión con el sentido del acto, de la realidad que la misma autora revela como ensoñaciones:

La ensoñación ${ }^{14}$ más allá del legado de puntos de vista y actitudes sociales codificados, conserva la rilkeana capacidad de asombro de ese niño interior que toma

\footnotetext{
${ }^{10}$ Intereses culturales que también revelan la ascendencia del tono y estilo narrativo parecido a la escritura talmúdica o al de la Cábala.

${ }^{11}$ ELIZONDO. Cuaderno de escritura. Remitimos nuevamente el texto citado al considerar la frase "instants of being" como si fuese la necesaria expresión "mágica" y cuya función fuese el acto de "abrir" el recuerdo: el milagroso "abracadabra", que Elizondo considera como la implosión memoriosa.

${ }^{12}$ No estamos ajenos al pensamiento del gerundio como infinitivo en el pensamiento de Heidegger; sin embargo, el enlace adoptado por la autora es Gaston Bachelard. Aquí hacemos caso a esa intencionalidad interpretativa para remitirnos a una forma particular de concebir el "instante poético" que se significa en la arquitectura de la memoria.

${ }^{13}$ BACHELARD. La intuición del instante, p. 21.

${ }^{14}$ El término ensoñación fija la atención de la autora en el pensamiento no sólo de Bachelard, también de Freud. En La interpretación de los sueños se alberga como ensoñación la realización de los deseos que en gran parte tienen su base en las impresiones provocadas por sucesos infantiles. El ensueño (diurno) y el juego forman parte del deseo.
} 
sus sueños por realidades, esa chispa inextinguible que aspira perpetuamente a lo divino [...] Sí, invento, me gana la imaginación, me subyuga el cerco numinoso de lo indefinible, el halo de las quimeras, de las imágenes poéticas: "Soy un soñador de palabras escritas", insiste Gaston Bachelard. ${ }^{15}$

Siguiendo a Bachelard, hay una tensión de infancia en el fondo de cada ser avivada por la palabra poética. Los poetas "hacen revivir repentinamente nuestros recuerdos y reimaginar nuestras imágenes, a partir de las palabras bien reunidas [...] Hay que embellecer para restituir". ${ }^{16}$ Para este filósofo tiene sentido hablar de la infancia dentro de un contexto poético del hombre, en la poesía existe una fuerza de síntesis de la vida íntima y el acontecer humanos, "soñada y meditada, meditada en la intimidad misma de la ensoñación solitaria, la infancia toma la tonalidad de un poema filosófico". ${ }^{17} \mathrm{La}$ infancia "reimaginada" a través de la ensoñación que en Seligson se quiere poética o literaria, encuentra desde el título del libro ${ }^{18}$ el tono del adulto en un inevitable pesimismo heredado por el sentimiento de exilio ancestral que repite un sentimiento de orfandad que extiende su sentir en la poesía (instants of being), que persiste en esta "Esther que no acaba por entender que no va, no digamos ya a cambiar el mundo, sino nada más ni siquiera a modificarlo un poco, y ni qué decir de las personas". ${ }^{19}$ Seligson es el sujeto que escenifica discursivamente esta experiencia sensible que no encuentra cabal forma de congraciarse consigo misma salvo poéticamente. Será por ello que el libro despliega y confronta anécdotas que condicionan el revés de las cosas, personas y situaciones, éstas se mantienen como objetos los semióticos que se reproducen e ingresan en el diario de viaje, en esta especie de bitácora fechada por las instantáneas o imágenes familiares que temporalmente marcan un itinerario factible en la memoria.

\footnotetext{
${ }^{15}$ SELIGSON. Todo aqui es polvo, p. 92.

${ }^{16}$ BACHELARD. La poética de la ensoñación, p. 175.

${ }^{17}$ BACHELARD. La poética de la ensoñación, p. 192.

${ }^{18}$ El título proviene directamente de un enunciado de Geney Beltrán Félix "Se desdobla el viento en remolinos que enturbian la vista. Todo aquí es polvo". La expresión completa se incluye como epígrafe en la cuarta parte del libro: "Una ventana con la cortina al aire". ${ }^{19}$ SELIGSON. Todo aqui es polvo, p. 151.
} 
La madre, el padre, la hermana, los hijos, las nietas, el marido, los amigos filósofos, las amigas intelectuales y los amores, son entidades que porfían con las imágenes disfóricas y la nostalgia de ninguna parte. Cada estancia convertida en capítulo reproduce las pautas de ese viaje que concluye "Aquí, hoy en este 2003, me deslizo por un borde oscuro, doy testimonio de él todos los días, hay muerte a un lado y otro, muerte, así a secas [...] a ambos lados del borde del insomnio". ${ }^{20}$

Entre la pausa de la vida y del ensueño, la aprehensión y la anticipación de lo vivido se concibe en el sentido de las inevitables preguntas o (re)flexiones que a su vez convocan no una respuesta sino un coro de voces invisibles que no le permiten liberar el sentido de pérdida. Los atesorados "instants of being" se pronuncian para imponer un sentido inducido como el ritmo poético de la prosa, semejante a un estribillo de una última morada (aquí todo es polvo), cuya imagen toma cuerpo en la fugacidad, temible y obsesiva del tiempo, en donde Esther Seligson elabora el recuento final de "las pesadillas o de los miedos". Si la leemos acuciosamente en referencia a la interioridad del propio cuerpo que pone en perspectiva el recuerdo, el adentro y el afuera de lo que siente y percibe, encontramos que esos instantes preservados con énfasis no serían nada si no se transformaran en imagen, en palabra escrita.

Recorramos el libro del final al inicio para refigurar la idea que lo produce ante la inminencia del sentimiento: "Ya me cansé de ser fuerte. Estoy hecha de polvo y sufro", ${ }^{21}$ clama la narradora. Y si repasamos la trama del inicio al final, veremos el primero de esos instantes de plenitud en la emoción del recuerdo, cuando los regalos señalaban la infancia temprana. El segundo instante ocurriría muchos años después, desde una perspectiva literaria cuando media la aprehensión poética que sugiere Bachelard, pues fue al leer La semana de colores de Elena Garro que "el secreto cromático y de textura de esos instants of being fuera de la "realidad' y tan carnalmente reales" 22 tuviera efecto. El tercer instante, también evocado literariamente, pero a la manera de Proust, traslada el vuelco poético de los sentidos que nos remiten a la famosa escena de las magdalenas remojadas en té, en analogía con la fragancia y deleite provocados por la nata fresca preparada por la abuela y "que utilizaba

\footnotetext{
${ }^{20}$ SELIGSON. Todo aqui es polvo, p. 157.

${ }^{21}$ SELIGSON. Todo aqui es polvo, p. 179.

${ }^{22}$ SELIGSON. Todo aquí es polvo, p 56.
} 
en la confección de sus menjunjes faciales; el resto se extendía sobre el lunch que mi hermana y yo llevábamos a la escuela". ${ }^{23}$ Este memorable recuerdo provocado por la "nata fresca" se agria finalmente cuando no se puede sostener en el recuerdo: “¿Miedo a la muerte? No: a lo que muere, a la neutralidad afectiva, al insidioso silencio [...] a esos hoyos negros que es la memoria". ${ }^{24}$

Enunciar el recuerdo y aclarar el pensamiento son formas de aceptar que saber no es conocer o que saberlo todo no indica que lo comprendemos, la incertidumbre impulsa a esta Sherezade a relatar la vida propia intentando salvarse o destruirse entre las rachas de arena que amenazan hundirla. Los enunciados celebran instantes de plenitud que se interrumpen enseguida con frases como aquellas y como ésta: "Claro que me hubiera gustado ser feliz", le confiesa a una amiga: "La tarde, con un dejo de película de Marguerite Duras, el tono del cielo, la lentitud de nuestros gestos y diálogos, la playa vacía. ${ }^{25}$ Pero, "uno necesita desollarse muchas veces para encontrar detrás de la piel vieja su propio mundo interno". ${ }^{26}$

La incierta percepción de la realidad que toda escritura literaria crea, sea o no autobiográfica porque si no se vive se desea y/o finge vivir, busca y encuentra sentido poético en lo que la misma Seligson califica como herencia de raíz hebrea, sobre todo al dudar sobre si lo que cuenta y recuerda es real de verdad o verdadero de "deveras". El conglomerado de imágenes y de especulaciones entran en conflicto con las experiencias sensibles o reales de su núcleo familiar/cultural; sobre ella pesan sus propios conflictos neuróticos (como los del cualquier humano) más las secuelas o trasplantes de toda migración de padres a hijos. "Dentro del margen familiar, el hijo que logra sobresalir cuenta tanto con el apoyo de sus objetos externos reales [...] como con la aprobación de sus objetos internos buenos" ${ }^{27}$ Así pues, esa verdad (de verdad) que la narradora busca en la acción de narrar el pasado familiar y de narrarse dentro y al calce del mismo, requiere de "hurgar en los poemas memorizados cual oraciones sacras, esos alvéolos de espacio y tiempo comprimidos en las imágenes,

\footnotetext{
${ }^{23}$ SELIGSON. Todo aqui es polvo, p. 81.

${ }^{24}$ SELIGSON. Todo aqui es polvo, p. 97.

${ }^{25}$ SELIGSON. Todo aqui es polvo, p. 77.

${ }^{26}$ SELIGSON. Todo aqui es polvo, p. 77.

${ }^{27}$ GRINBERG; GRINBERG. Migración y exilio, p.160.
} 
las frases, las letras, comas, puntos, instants of being, que, si he de ser franca, no en todos los orgasmos encontraría después". ${ }^{28}$ Esos "alveolos" se colman de momentos y escenarios removidos, como dijimos antes, en ese último viaje y estancia final en Jerusalem: "una ventana con cortina al aire, rostros, donde los acontecimientos, reminiscencias, recuerdos, lograron quedarse apresados, y amalgamarse distantes y distintos, detenidos en una simultaneidad". ${ }^{29}$ A partir del "instante poético" en la conjetura de Bachelard, ${ }^{30}$ reflexionemos nuevamente sobre la emergencia de esta memoria no como un tiempo continuo o encadenado, sino detenido en la verticalidad de lo simultáneo que una poesía ofrece. ${ }^{31}$ Lógico que eso que está oculto, abajo (en la disposición vertical de un poema) y en el revés (en la narrativa), es un recurso que apoya lo silenciado y nefando que provoca en la autora repetir la pregunta de Edmond Jabès: ¿“[...] cuándo voy a escribir algo que no sea a partir del dolor"? ${ }^{32}$ La voz que enuncia y escucha (narradora y narrataria) decide enfatizar en este libro el venero de su angustia, de "esas raíces heridas que se desmoronan":

[...] túneles donde reencontrarnos, y reencontrar esas raíces heridas que se desmoronan en la sangre, generación, tras generación, y en el desconsuelo común de lo que no se dice quizá para no herir más, quizá porque al final, el polvo dará

${ }^{28}$ SELIGSON. Todo aqui es polvo, p. 94,

${ }^{29}$ SELIGSON. Todo aqui es polvo, p. 163.

30 "Que se tome el instante poético del lamento sonriente, en el momento mismo en que la noche duerme y estabiliza las tinieblas, en que las horas apenas respiran y en que la soledad por sí sola es ya un remordimiento. Los polos ambivalentes del lamento sonriente casi se tocan" (BACHELARD. La intuición del instante, p. 98).

${ }^{31}$ No olvidemos que Ester Seligson cultivó también la poesía, que buscó en la armazón de un poema el contraste figurativo con la estructura narrativa de la ficción y del ensayo. Entre la propuesta de Bachelard (la forma lírica) y el estilo antiguo de la melitzá (Ver nota seis) podemos encontrar el antecedente que estructura todos los textos de nuestra autora. Agrego una nota más acerca de la importancia temporal en la estructura del poema "En todo poema verdadero se pueden encontrar los elementos de un tiempo detenido, de un tiempo que no sigue el compás de un tiempo que llamaremos vertical para distinguirlo de un tiempo común que corre horizontalmente como el agua del río y con el viento que pasa [...] mientras que el tiempo de la prosodia es horizontal, el tiempo de la poesía es vertical" (BACHELARD. La intuición del instante, p. 94). Sirva la cita al considerar la prosa poética que acuña Seligson en su obra.

${ }^{32}$ SELIGSON. Esther Seligson, la escritura revelada. 
cuenta de todas nuestras querellas y ningún arqueólogo vendrá a descubrir entre los escombros de nuestras exiguas geografías y el subsuelo de nuestra Graishland prometida, una Jerusalem subterránea, una Advat floreciente hundida en el desierto, un oasis de aguas curativas a orillas del Mar Muerto que se seca día con día, o unas cuevas que se esconden en rollos manuscritos. ${ }^{33}$

Esta bitácora escrita sobre las balsas "donde refugiamos los naufragios, los sucesivos hundimientos" ${ }^{34}$ colma el universo figurativo del primer relato evocando a las mujeres en la relación madre e hijo/ hija "esa lenta erosión que configuró la topografía de nuestro mundo infantil". El asunto de calificar los instants of being como las huellas que den cuenta y aprehenden lo imaginario y lo sensible, contrastan la refiguración de las vivencias de la madre y del padre.

La madre cruzó "desde algún puerto de la Rusia aún zarista el océano grande" y, al contario de la hija, no escribiría las minuciosidades que dejó atrás, sólo reservaría para sí misma los objetos y el gusto por la ópera en donde sus "despilfarros" encontrarían algún ajuste de cuentas a su pasado:

Pienso - conjetura la narradora- que lo que en realidad la consoló fue la esperanza de una nueva oportunidad para escoger otra forma de vida, otro cuerpo, deshacerse de sus angustias y de su latente temor [...] no fuera de verdad a encontrarse del otro lado esperando compartir con nosotros la cena conmemorativa del Éxodo. ${ }^{35}$

El retrato del padre se concibe, más que con los actos, con el recurso poético "la memoria literaria y ni hablar de la amorosa. Y no es cuestión de paso del tiempo [...] sino de intensidad, de odio, de privilegiar remembranzas, subjetividades susceptibles, es cuestión de cómo reinterpretamos en el momento, y más tarde, tanto la realidad como su sentido" ${ }^{36}$ El padre que pudo huir de la tragedia de los inicios de la Segunda Guerra Mundial y el ascenso de Hitler, resintió, al igual que la

\footnotetext{
${ }^{33}$ SELIGSON. Todo aqui es polvo, p. 32.

${ }^{34}$ SELIGSON. Todo aqui es polvo, p. 34.

${ }^{35}$ SELIGSON. Todo aqui es polvo, p. 21.

${ }^{36}$ SELIGSON. Todo aqui es polvo, p. 37.
} 
madre, un destino que no había escogido. Para la autora lo que le hizo falta al padre era poder llorar y ser consolado con un abrazo, "ese largo abrazo que nunca recibió de niño ni de adolescente cuando su madre lo despidió a la puerta de casa en un pueblucho cercano a algún afluente del Vístula". ${ }^{37}$ Tanto él, "Carlos", (Szlome Zeligson) como "Max", el menor y "Jack", que se quedó en Oklahoma, vivieron un "destino":

$\mathrm{Al}$ menos así se le desmorona a uno el piso bajo los pies de un irreversible trancazo. Sobrio, prudente, replegado en sus emociones, no quiere oír para no enterarse, no pregunta para no estar obligado a responder: mi padre, un ser desgarrado por el exilio -ya de por sí un judío es en cualquier sentido un sobreviviente-, por un sentimiento de perpetuo naufragio, de perpetuas interferencias. ${ }^{38}$

Quien piensa en la orfandad, puesto que de alguna manera todos los hijos habían sido herederos del exilio, el cronotopo de la Shoah asienta la encarnación y la ambigüedad de su experiencia, al final cuenta como principio arbitrario de esa diáspora del padre heredada a las hijas para que al final sea una, la escritora, quien parta o ¿regrese? a Jerusalem para poder 'abrir las ventanas al aire' y no quedarse en perpetua soledad "mariposas pinchadas dentro de una caja de cristal". ${ }^{39}$ En esos vientos legendarios o míticos, vivenciales y recalcitrantemente actuales, que la impulsaran a una reinterpretación de sí misma en su viaje a Jerusalem con la carga de la herencia exiliar, Seligson perpetúa la íntima convicción de que no encontrará la tierra prometida. A pesar de sus recorridos por las calles "silenciosas del Shabat con los versos de Rilke en mano" era difícil resolver el enigma del propio interior, de ahí su recurrencia a otros saberes que le proporcionaran la respuesta que no encuentra, "pues igual todo aqui es polvo". ${ }^{41}$ La ascendencia del pensamiento judío en el mismo Freud, en Jabès, en Steinsaltz está en la propia negación que el psicoanalista argumentara. Incluso citando a Camus ella protesta: “¿Es Camus quien dice que las autobiografías se escriben en el fondo para autojustificarse? Aquí, ni lo uno ni lo otro: aquí todo es polvo, y yo tomo

\footnotetext{
${ }^{37}$ SELIGSON. Todo aquí es polvo, p. 41.

${ }^{38}$ SELIGSON. Todo aquí es polvo, p. 41.

${ }^{39}$ SELIGSON. Todo aquí es polvo, p. 50.

${ }^{40}$ SELIGSON. Todo aquí es polvo, p. 161.

${ }^{41}$ SELIGSON. Todo aquí es polvo, p. 161.
} 
la forma que necesito para entablar un diálogo". ${ }^{42}$ Esta negación consigo misma, en su interdicción, decide y confecciona el último espacio del viaje y de la escritura justo en Israel, con esa postrera voz y mirada que quisiera salvar a fuerza de ser irónica, al pensar en lo perfectamente real que pudiera sucederle: "Las estadísticas consignan que en Jerusalem se concentra la mayor cantidad de suicidas y de locos proporcional al número de habitantes, no sólo del país sino del mundo". ${ }^{43}$

El "hambre de recobrar la infancia" cruza trágicamente la realidad del suicidio. A partir de las imágenes de la madre y el padre, se añade esa otra infancia, la de su hijo que se suicida a los treinta años,

ese niño de cuatro años que estrecharía yo en delante entre mis brazos hasta que se me fue volando por la ventana once pisos abajo. Nombrar las cosas por su nombre es sacarlas de la oscuridad y elevarlas hacia la Luz, reiteran los cabalistas. ¿Cómo vivió ese niño hasta su muerte treinta años después buscando amortiguar la cuota de dolor que traía asignada? ${ }^{44}$

El universo de la infancia regresa en el dolor y entonces en la muerte. Esa retórica que centra el léxico de los afectos y de su reflexión se convierte en el acto reminiscente, pero aquí son las pasiones nombradas, verbalizadas y adjetivadas (simples o complejas), las que dan más que verosimilitud, una forma de existencia a ese algo de antes, ese algo ambiguo que paradójicamente se nombra y se esconde en el discurso que profiere Seligson: "Con tantas palabras como hay para decir las cosas ¿dónde van a parar las que quedan silenciadas?, ¿cómo esgrimirlas sin violencia cuando agreden, atemorizan u ofenden?" 45 La imposibilidad de preservar al niño (a su niño) del dolor, conduce incansablemente a la narradora a la infancia y a su invocación poética en su sed "del abrazo que nos torne invulnerables a la orfandad, al miedo, a la indigencia e incompletud que nos viene desde "el silencio de los orígenes". ${ }^{46} \mathrm{El}$ sentimiento de infancia en el cruce del sentimiento exiliar y la supuesta "cuota de dolor que traía asignada" se convierte en el objeto que origina

\footnotetext{
${ }^{42}$ SELIGSON. Todo aqui es polvo, p. 108.

${ }^{43}$ SELIGSON. Todo aqui es polvo, p. 165.

${ }^{44}$ SELIGSON. Todo aqui es polvo, p. 89.

${ }^{45}$ SELIGSON. Todo aqui es polvo, p. 32.

${ }^{46}$ SELIGSON. Todo aqui es polvo, p. 88.
} 
la entrada al umbral y a la estirpe. Seligson transforma esa su infancia y la del otro (padre, hijo) en el factor más poderoso del destino de la creación. Si por una parte hallamos ese sentimiento como mera reiteración, por otra es que resulta el móvil más aludido poéticamente, Paul Celán, en El Meridiano (1960), afirma buscar el lugar originario:

Busco también, puesto que estoy de nuevo donde empecé, el lugar de mi propia procedencia. Busco todo eso, es cierto, con dedo muy impreciso, porque inquieto, sobre el mapa-sobre un mapa infantil, como inmediatamente debo confesar. Ninguno de estos lugares puede encontrarse, no los hay, pero yo sé dónde tendría, sobre todo ahora, que haberlos, y... iencuentro algo! [...] Hallo lo que vincula y, como el poema, conduce al encuentro. Hallo algo-como el lenguaje-inmaterial, pero terreno, terrestre, algo en forma de círculo, que vuelve sobre sí a través de ambos polos, y -de modo más jovial-que, al hacerlo, cruza incluso los trópicos, los tropos: hallo... un meridiano. ${ }^{47}$

A raíz de la búsqueda de sí, el cúmulo de situaciones y remembranzas cobra significación en cada uno de los episodios y los efectos de éxodo en los descendientes de inmigrantes que se descuellan en el medio familiar, sobre todo cuando "el duelo del trasplante no ha sido elaborado por la generación que ha emigrado". ${ }^{48}$

\section{Conclusiones}

El "síndrome seligson" orienta una identidad que se forja en el contexto familiar, pero también en el cultural. En Seligson como en otras escritoras de ascendencia judía (Sabina Berman, Ethel Krause, MuñizHuberman, Margo Glantz, entre otras), puede aplicarse lo que Judith R. Baskin (1994) opina de las escritoras latinoamericanas que comparten esta estirpe, que es justamente su ambivalencia hacia el significado de una identidad judía y en el convencimiento de la centralidad de tal judeidad en sus vidas y en su escritura. La prevalencia de lo hebraico marcha al lado de una mexicanidad evidente en el lenguaje y en la manera en que todas estas escritoras lo incluyen, en los contextos, en los mitos, y también en

${ }^{47}$ CELÁN. El Meridiano.

${ }^{48}$ GRINBERG; GRINBERG. Migración y exilio, p. 167. 
la manera en que su mexicanidad se incorpora entre el saber poético y los referentes culturales. Hay que considerar que la ola feminista de su época no era un hito problemático ni en sus literaturas ni en sus vidas. El estilo de estas escritoras busca la trascendencia de lo literario universal, aunque la tradición cultural hebraica revele su ascendiente en el giro de su apelación, y, pese a que, como asegura Seligson, se acepte sólo como mero "estanco" cultural. ${ }^{49}$

La condición narrativa hecha de papel, líneas y palabras confecciona la fantasía, el mundo ficcional de un autor, pero hay que fijar también la atención en la incertidumbre de lo relatado, pues esa figura, narcisista al fin, determina a quien tiene ante sí como una persona "real" en el universo figurativo del relato literario, cuando se desdobla, se acepta y se niega en tantas imágenes como sea capaz de querer, soñar, desear y exorcizar. En la lectura de Todo aqui es polvo se halla también lo ominoso en esta actitud, en esa reiteración permeable, en la atribución de un pertinaz retorno del sí-mismo multiplicado en la implicación autoral. Todo aquí es polvo no es sólo un relato autobiográfico ni un palimpsesto que surge sobre las muchas capas que encubren/descubren las citas citables de filósofos, poetas, artistas. Quienes moldean en la palabra la imaginación describen el retrato de una artista que enfrenta a la muerte real con la muerte temporal, porque prevalece en el recuerdo forzosamente literario. Solo así se reúnen las condiciones válidas, tanto para el vivenciar como para la experiencia estética, en un libro que a propósito carece de límites genéricos.

\section{Referencias}

BACHELARD, Gastón. La intuición del instante. Ciudad de México: Fondo de Cultura Económica, 2000.

BACHELARD, Gastón. La poética de la ensoñación. Ciudad de México: Fondo de Cultura Económica, 1998.

BASKIN, Judith R. (Ed.). Women of the Word: Jewish Women and Jewish Writing. Detroit: Wayne State University Press, 1994.

\footnotetext{
${ }^{49}$ En varias entrevistas, la escritora reiteraba su rechazo a todas las ortodoxias en las que canónicamente la incluyen como "Escritoras judías" (cf.SELIGSON. Esther Seligson, la escritura revelada).
} 
CELÁN, Paul. El Meridiano. Disponible en: $<$ https://exilsite.files. wordpress.com/2012/12/elmeridianocelan.pdf $>$. Acceso en: 15 dic. 2017. ELIZONDO, Salvador. Cuaderno de escritura. Ciudad de México: Fondo de Cultura Económica, 2000.

GENNEP, Arnold van. Los ritos de paso. Madrid: Taurus, 1986.

GRINBERG, León; GRINBERG, Rebeca. Migración y exilio: estudio psicoanalítico. Madrid: Biblioteca Nueva, 1996.

JABÈS, Edmond. El libro de las preguntas. Madrid: Siruela, 2006.

MOLLOY, Silvia. Acto de presencia: la escritura autobiográfica en Hispanoamérica. Ciudad de México: COLMEX/Fondo de Cultura Económica, 2001.

MUÑÍZ-HUBERMAN, Angélica. El siglo del desencanto. Ciudad de México: Fondo de Cultura Económica, 2015.

SELIGSON, Esther. Esther Seligson, la escritura revelada. Ciudad de México, c2011. Entrevista concedida a Miguel Ángel Quemain. Disponible en: $<$ https://literatura.inba.gob.mx/entrevista2/3268-seligsonesther-entrevista.html>. Acceso en: 4 mayo 2015.

SELIGSON, Esther. Todo aqui es polvo. Ciudad de México: Bruguera, 2010.

ZAMBRANO, María. Persona y democracia. Madrid: Siruela, 1996.

Recebido em: 26 de janeiro de 2018. Aprovado em: 9 de abril de 2018. 